\title{
Apontamentos sobre os espaços sócio-ocupacionais da Pedagogia não escolar
}

\author{
Sandrielli Cassiano de Carvalho ${ }^{1}$ \\ Fernando Guimarães Oliveira da Silva²
}

\begin{abstract}
Resumo
A Pedagogia é uma área que tem ampliado a concepção de educação como objeto de trabalho, considerando as novidades de atuação que as Diretrizes Curriculares Nacionais do ano de 2006 oferecem. Ao lecionar a disciplina de 'Educação em espaços não escolares' em Curso de Licenciatura em Pedagogia, objetivou-se deslocar o imaginário das estudantes sobre as possibilidades de atuação do/da pedagogo/a até então ligadas ao ambiente escolar. A partir da pesquisa bibliográfica e da pesquisa empírica, as estudantes foram levadas a investigar os espaços sócioocupacionais da Pedagogia não escolar nos municípios onde moravam. Encontramos pedagogos/as que atuam na assistência social e na saúde mental, o que nos levou a investigar como a Pedagogia se efetiva nesses espaços. Concluímos que a produção do conhecimento científico na área educacional acompanha a execução do trabalho pedagógico realizado nesses novos locais de atuação.

Palavras-chave: Pedagogias; Educação não escolar; Formação do/a pedagogo/a.
\end{abstract}

\section{Notes on the socio-occupational spaces of pedagogy no school}

\begin{abstract}
The Pedagogy is a area that has broadened the concept of education as a work object, considering the novelties of action that the National Curriculum Guidelines of the year 2006 brings. By teaching the discipline of 'Education in spaces not Students 'Degree in Pedagogy, we aimed at displacing the students' imaginary about the possibilities for the pedagogue's action. From bibliographical and field research, the students were led to investigate the sociooccupational spaces of Pedagogy outside the school environment. We found educators who work in social assistance and mental health, which led us to investigate how Pedagogy is effective in these spaces. We conclude that the production of knowledge in the education field as joined by the execution of the pedagogical work carried out in these new places of agency.

Keywords: Pedagogy; Non-school education; Formation of the pedagogue.
\end{abstract}

\section{Considerações iniciais}

De início, nosso objetivo é causar impacto. Começar com elementos que já provocam os/as leitores/as, pedagogos/as, profissionais da educação, futuros/as pedagogos/as e a quem interessar. Problematizar que, a partir da atuação de pedagogos/as nos espaços sócioocupacionais não formais, também se produz conhecimento e, sobretudo, como bem pontuam Miranda e Silva (2017) precisam ser estudados para se criar outras práticas:

\footnotetext{
${ }^{1}$ Associação de Ensino e Cultura de Mato Grosso do Sul, Três Lagoas, sandycarvalho15@hotmail.com.

2 Universidade Estadual de Mato Grosso do Sul, Paranaíba, fernando.oliveira@uems.br.
} 
Historicamente, a resistência de abertura ao novo da Pedagogia estabelece-se por conta de sua cultura em estar organizada sob a lógica dos processos de escolarização da infância, bem como da organização do trabalho pedagógico na/para/pela Escola (MIRANDA; SILVA, 2017, p. 87)

Propomos partir dessa reflexão para tratar do objeto de trabalho do/da pedagogo/a. Com a leitura de Miranda e Silva (2017), acredita-se que o impacto proposto foi atingido. O de problematizar as construções que temos a respeito do Curso de Pedagogia, desfocando-o do estereótipo de que só forma professores/as.

Desfocar, então, é produzir deslocamento. O convite realizado permite pensar o novo no contexto do campo de atuação dos/das pedagogos/as que não atuam no ambiente escolar. Pensar na Pedagogia como um campo de produção de saberes que se articula com demandas apresentadas em outras áreas de atuação que não se imaginavam possíveis para pedagogos/as. Produzir o deslocamento do estereótipo de Pedagogia essencialmente escolar para abri-la à experimentação de novos campos de atuação.

Este estudo é resultante de debates que ocorreram durante a disciplina de "Educação em espaços escolares e não escolares", cursada no campo da formação do Curso de Licenciatura em Pedagogia. Tratamos de vários contextos sócio-ocupacionais cuja possibilidade de existência não imaginávamos, dada a visão anterior de que entraríamos no Curso de Pedagogia com único propósito de atuar na educação da infância ${ }^{3}$. Ou em atividades ocupacionais que estariam ligadas ao espaço escolar: supervisão, orientação, coordenação ou gestão da educação. A novidade do assunto nos deixou encantadas com a imensidão de possibilidades de atuação para Licenciados/as em Pedagogia.

Articulada com a necessidade de a pesquisa de práticas pedagógicas serem um parâmetro essencial na formação do/da pedagogo/a, as estudantes fizeram uma pesquisa de campo em suas cidades de origens para que pudéssemos ter condições de investigar os diferentes espaços sócio-ocupacionais e analisar o que a literatura tem produzido sobre a atuação nesses espaços. Trata-se de três municípios situados em região de divisa, dois no Estado de Mato Grosso do Sul

\footnotetext{
${ }^{3}$ A compreensão de infância aqui colocada refere-se ao adotado pelo Estatuto da Criança e do Adolescente (ECA, 1990) no artigo 20: "Art. 2ㅇ Considera-se criança, para os efeitos desta Lei, a pessoa até doze anos de idade incompletos, e adolescente aquela entre doze e dezoito anos de idade (BRASIL, 1990, s/p)".
} 
(Brasilândia ${ }^{4}$ e Três Lagoas) e um no Estado de São Paulo (Guaraçaí).

Apesar de a instrumentalidade ser rígida a ponto de nos dizer que não deveríamos apontar os nomes dos municípios, acreditamos que este fator tem relevância, uma vez que nos dá condições de situar melhor a pesquisa. O levantamento inicial tratou de explorar unidades do poder público, Organizações da Sociedade Civil (OSC) e empresas localizadas no âmbito municipal para tabulação.

Munidas/o desses dados, podemos conhecer a realidade local dos municípios analisados. Vimos que, nos municípios de pequeno porte (Brasilândia/MS e Guaraçaí/SP, que têm população entre 8 e 10 mil habitantes) não foi possível encontrar nas Unidades Não escolares Municipais, os/as pedagogos/as. Diferente foi o caso de Três Lagoas/MS, onde já foi possível encontrar tais profissionais atuando em outros espaços que não o escolar.

Tal levantamento foi possível devido ao investimento das estudantes em práticas de pesquisa que trouxeram visibilidade aos dados e, também, que posteriormente nos possibilitaram pensar na aplicabilidade de pesquisa que nos oferecesse condições de compreender as práticas que estão sendo efetivadas pelos/as pedagogos/as não escolares. Este é, por sua vez, o foco da disciplina de "Estágio Supervisionado em Educação não escolar". Com esta prudência na pesquisa empírica, inicialmente realizada, analisamos os dados também sob a perspectiva da produção acadêmica na área, primando por conhecer também a produção realizada por pesquisadores/as da região sobre o assunto.

Demo (1994) afirma que a pesquisa empírica se relaciona com o tratamento fatual da realidade. É um tipo de pesquisa que favorece maior contato com as argumentações: "[...] por mais tênue que possa ser a base fatual. O significado dos dados empíricos depende do referencial teórico, mas estes dados agregam impacto pertinente, sobretudo no sentido de facilitarem a aproximação prática" (DEMO, 1994, p. 37). Devido à não formalização por escrito para contato, levantamento e tabulação de pedagogos/as na educação não escolar, acredita-se que essa pesquisa seja inicialmente de base empírica.

\footnotetext{
${ }^{4}$ Os municípios de Brasilândia/MS e Guaraçaí/SP são considerados de pequeno porte I, de acordo com a Política Nacional de Assistência Social (PNAS/BRASIL, 2004), porque possuem população entre 0 e 10 mil habitantes. Já, segundo esse mesmo documento normativo, Três Lagoas/MS é considerada de grande porte I, porque tem população entre 100 e 200 mil.
}

Periódico Horizontes - USF - Itatiba, SP - Brasil - e020032 


\section{HSF HORIZON TES}

Para além da instrumentalidade empírica, ainda utilizamos os recursos bibliográficos para analisar o conteúdo empírico levantado no contexto das Secretarias das respectivas prefeituras contatadas. A pesquisa bibliográfica auxilia o/a pesquisador/a a explorar, descrever e detalhar aspectos filosóficos, procedimentos metodológicos e resultados de pesquisas realizadas na área de seu estudo. Propõem tal concepção Lima e Mioto (2007). Na leitura das autoras, a pesquisa bibliográfica é um guia de todo o processo de investigação e análise do/da pesquisador/a. Assim, segundo elas:

Finalizando, reafirma-se a pesquisa bibliográfica como um procedimento metodológico importante na produção do conhecimento científico capaz de gerar, especialmente em temas pouco explorados, a postulação de hipóteses ou interpretações que servirão de ponto de partida para outras pesquisas (LIMA; MIOTO, 2007, p. 44).

Diante disso, nosso estudo se divide em três momentos. No primeiro, vamos analisar o que as diferentes produções teóricas têm afirmado sobre a Pedagogia como área de atuação, identidade profissional e sua atuação em outros espaços sócio-ocupacionais. No segundo, propomos discussões sobre o levantamento feito por meio da pesquisa empírica. Por fim, no terceiro, apresentamos as pesquisas encontradas na região sobre o assunto da atuação da Pedagogia nos contextos de educação não escolar.

\section{Perspectivas sobre a Pedagogia}

O caminho traçado para problematizar a Pedagogia como desvinculada da escola, que não seria, então, mais o único um destino dos/das pedagogos/as, orientou-se por questionar a história de formação de tais profissionais. Também se tratou dos marcos legais que trouxeram diferentes contestações no campo da formação docente para o/a licenciado/a atuar como docente e técnico/a da educação.

Fez-se pertinente, também, entender a dinâmica de construção da identidade profissional, por meio das diferentes perspectivas que compreendem a educação como desvinculada apenas do sistema escolar e aprendida em outros espaços. Esse assunto, por sua vez, trouxe consigo outro problema: a questão da Pedagogia compreendida como ciência da 
educação. Por meio desse conjunto decididamente teórico que visou a construir outras possibilidades para a prática do/da pedagogo/a, analisamos diferentes espaços sócioocupacionais e problematizamos aquele em que encontramos mais profissionais atuando: a área de proteção social junto ao Sistema Único de Assistência Social (SUAS) e a de cuidados em saúde mental oferecidos junto ao Sistema Único de Saúde (SUS).

Em seus estudos, Brzezinsk (2007, p. 229) examina a formação de professores de educação básica, mediante o percurso histórico de formulação de políticas educacionais à definição das atuais diretrizes curriculares nacionais estabelecidas para o curso de Pedagogia. Nele, a autora relata impasses existentes entre dois projetos educacionais contraditórios, resultantes da complexa relação entre o Estado e as forças sociais em torno do interesse coletivo instituinte no contexto da instituída burocracia governamental.

Nesse processo de discussões, Brzezinsk (2007, p. 230) objetiva explanar as concepções de formação de professores e apresentar a formação do/da pedagogo/a, os pareceres e a resolução que instituem as diretrizes curriculares nacionais. Para tanto, a autora atua como militante em busca da instalação de uma política global de formação de profissionais à educação básica e de profissionalização docente, em nosso país, com várias reivindicações à licenciatura em Pedagogia.

Outra questão contemplada refere-se ao processo de construção das diretrizes curriculares nacionais para formação de professores da educação básica, que foi marcado por momentos de tensão entre o instituinte e o instituído ${ }^{5}$. Aspectos presentes durante o processo de elaboração das diretrizes curriculares nacionais para o curso de Pedagogia, entre os representantes instituídos de poder de decisão no Conselho Nacional de Educação (CNE) e por representantes instituintes das associações.

Consoante o cenário atual, acentuamos tais ponderações a partir da leitura de Brzezinsk (2007) com destaque para o papel de formação humana que a educação assume frente às necessidades contemporâneas sobre novas formas de ser, saber e saber ser.

Então, ao levar em consideração as sucessivas mudanças ocorridas no curso de

\footnotetext{
${ }^{5}$ Referem-se, respectivamente: aos momentos de instabilidade ou conflito e às situações de estabilidade ou consensuadas/negociadas.
}

Periódico Horizontes - USF - Itatiba, SP - Brasil - e020032 
Pedagogia, resultantes de "[...] orientações advindas de leis, decretos, portarias ministeriais, resoluções e pareceres e de projetos em disputa no campo da educação" (BRZEZINSK, 2007, p. 236), a autora apresenta uma breve retrospectiva histórica, acentuando as diferentes identidades desse curso e o contexto atual das políticas de formação de professores.

Em seguida, expõe um balanço dos resultados da negociação, no qual destaca alguns aspectos adquiridos no diálogo entre o instituinte versus o instituído, de modo a construir uma Diretriz Curricular Nacional (DCN) para o Curso de Pedagogia. Segundo ela:

A docência é a base da identidade do pedagogo; A base comum nacional deverá ser respeitada; $A$ concepção de docência é explicitada; $O$ pedagogo não é formado exclusivamente para a docência para a educação infantil e anos iniciais do ensino fundamental; A formação para a gestão educacional e para pesquisa estão asseguradas; As habilitações foram extintas; A organização curricular por disciplinas poderá ser superada; e A experiência docente é pré-requisito para o exercício profissional de quaisquer outras funções de magistério (BRZEZINSK, 2007, p. 245-8).

Em discussão sobre essa temática, Libâneo (2006) problematiza que essa DCN da Pedagogia reacende o debate em torno da natureza do conhecimento pedagógico, do curso de Pedagogia, dos cursos de licenciatura para a formação de professores/as e do exercício profissional de professores/as e especialistas em educação.

Para subsidiar suas conceituações, o autor expõe criticamente os conteúdos do documento, posto que "[...] não contribuem para a superação de problemas acumulados na legislação sobre o assunto e, por isso, pouco avança na promoção da melhoria qualitativa das escolas de educação básica do país" (LIBÂNEO, 2006, p. 843). Portanto, devem ser alvos de investigação, reflexão e novas abordagens.

Segundo o autor, a problemática instaura-se desde a falta de clareza conceitual à imprecisão na definição da Pedagogia e da atividade profissional do/da pedagogo/a. As definições operacionais tornam-se muito confusas para a atividade profissional do/a pedagogo/a; como exemplo: a ambiguidade de nomenclatura do curso de licenciatura/bacharelado em Pedagogia, como também, as imprecisões normativas. Assim:

A Resolução do CNE, pela precária fundamentação teórica com relação ao campo conceitual da pedagogia, pelas imprecisões conceituais e pela 
desconsideração dos vários âmbitos de atuação científica e profissional do campo educacional, sustenta-se numa concepção simplista e reducionista da pedagogia e do exercício profissional do pedagogo, o que pode vir a afetar a qualidade da formação de professores de educação infantil e anos iniciais (LIBÂNEO, 2006, p. 848).

Em decorrência, o autor frisa que a legislação, contudo, tem um papel importante no funcionamento dos sistemas de ensino e das práticas escolares e aponta consequências que acarretam. Logo, o autor propõe uma base teórico-crítica para uma Pedagogia engajada em problemas reais, isto é: frente à realidade atual do mundo, é necessário que seja pensada a sua complexidade. O foco centraliza-se em:

[...] Pensar e atuar no campo da educação, como atividade social prática de humanização das pessoas, implica a responsabilidade social e ética de dizer não apenas por que fazer, mas o quê e como fazer. Isso envolve necessariamente uma tomada de posição pela pedagogia, na qualidade de dispositivo teórico e prático de viabilização das práticas educativas. (LIBÂNEO, 2006, p. 865).

Em se tratando das dimensões de abordagem da Pedagogia, sobre a compreensão ampla da Pedagogia, o autor distingue três dimensões de sua abordagem: a epistemológica, a dos saberes práticos e a dos saberes disciplinares. A dimensão epistemológica diz respeito à reflexão crítica sobre o exercício das práticas e das intencionalidades das ações pedagógicas cotidianas. A dimensão prática refere-se ao modo de agir pedagógico articulando saberes e fazeres. Já a dimensão disciplinar constrói-se por meio dos saberes tornados inteligíveis pelo exercício da ciência pedagógica sobre as práticas, dos saberes teóricos e das exigências postas pela sociedade com relação a propósitos formativos dos sujeitos.

De acordo com o autor, com essas três dimensões integradas à Pedagogia, é possível elencar as perspectivas das teorias a partir da prática, mediante planejamento de estratégias didáticas e investigativas que darão suporte aos saberes pedagógicos, pela atuação prática e ações críticas desenvolvidas pelos docentes. Com efeito, é neste caminho que professores/as e pedagogos/as-especialistas devem caminhar para alcançar êxito em suas funções.

Cruz (2011) também traz contribuições à reflexão sobre a temática: realiza uma pesquisa a partir de dados obtidos, e investiga a relação entre a teoria e a prática. Para tanto, percorre os aspectos históricos da gênese do curso de Pedagogia e de diferentes momentos que marcaram 
sua trajetória, assim como aborda a conexão bastante problemática no campo da formação.

Neste âmbito, a autora trouxe em debate a difusa relação entre a teoria e a prática, de modo a conceituar o histórico embate refletido na formação de professores. Outro aspecto ressaltado refere-se às atuais diretrizes curriculares para o curso de Pedagogia, suas possibilidades e limites teóricos e práticos para a formação de professores, em relação de interface quanto ao afastamento da teoria. A partir dos resultados de sua pesquisa, a autora salienta que:

Olhar o curso de pedagogia no Brasil com a visão dos pedagogos entrevistados, atentando para aspectos característicos dos tempos iniciais do curso e para as mudanças por ele sofridas, para analisar implicações, resistências e avanços em sua trajetória, possibilitou captar aspectos, dilemas, desafios e possibilidades que certamente são contributivos ao processo mais amplo de compreensão do papel da pedagogia na formação de professores (CRUZ, 2011, p. 162).

Desse modo, a autora frisa que, ao analisar o percurso da Pedagogia, nota-se que, hoje, com base nas diretrizes curriculares homologadas pelo Conselho Nacional de Educação (CNE) no ano de 2006, ainda há uma problemática na questão entre a teoria e a prática que, na verdade, deveriam estar imbricadas, para que a pedagogia postule novas formulações mediante as várias áreas que lhe são constitutivas.

\section{Em buscas de novos campos de atuação: entre os debates e projetos}

Para compreender melhor novas possibilidades de atuação da Pedagogia, decidimos provocar os conceitos que permeiam o campo da educação e, também, os locais em que são possíveis visualizar práticas relacionadas a ela. Com essa decisão, encontramos nos estudos de Gohn (2010, p. 16) conceitos relacionados à educação formal, não formal e informal. Compartilhamos da ideia de que a educação é essencial para o desenvolvimento integral das pessoas, independente dos locais onde é praticada e produzida. Traz impactos importantes em todas as áreas da nossa vida, seja social, econômica e cultural.

No âmbito da educação formal, o espaço em que ela é proposta oportuniza sua caracterização. Isto é, o ambiente escolar nos dá condição de caracterizar a formalidade que existe na relação com um conhecimento que é previamente instituído e sistematizado em 
currículos, planos de aulas e de ensino e outas formas de pensar conteúdos a serem apreendidos. Ocorre, assim, dentro de um sistema institucionalizado, ou seja, em escola, universidade; tem como agente o professor. Podemos utilizar a compreensão de Libâneo (1994, p. 177) para melhor definir a educação formal.

Na escola, a aula é a forma predominante de organização do processo de ensino. Na aula se criam se desenvolvem e se transformam as condições necessárias para que os alunos assimilem conhecimentos, habilidades, atitudes e convicções e, assim, desenvolvam suas capacidades cognoscitivas (LIBÂNEO, 1994, p. 177).

Compartilha da mesma ideia Gadotti (2005): segundo esse autor, a educação formal tem objetivos claros e específicos e é representada principalmente pelas escolas e universidades. Ela depende de uma diretriz educacional centralizada como o currículo, com estruturas hierárquicas e burocráticas determinadas em nível nacional, com órgãos fiscalizadores do ministério da educação. Gohn (2010) também concorda em seu pensamento sobre educação formal. Assim, define-a como vinculada a conteúdos previamente demarcados.

Em seguida, a análise nos leva a pensar outras formas de educação que estão distantes do formato supracitado. Trata-se de experiências da vida social com diferentes sujeitos envolvidos e que podem ter ou não organização. Uma das possibilidades assinalada pelos/as autores/as que estudam diferentes formas de educação é a questão da educação informal.

Pesquisando sobre o assunto, Gohn (2010) acredita que a educação informal ocorre com a família e com os/as amigos/as: através da interação com grupos sociais, valores e culturas herdadas são compartilhados de um/a para outro/a. É um forma de educação que ocorre por meio da sociabilidade, desenvolve modos de pensar e agir e hábitos, é um processo contínuo, através do qual a pessoa adquire e acumula conhecimentos, habilidades e percepções a partir das experiências do cotidiano. Esse tipo de educação ocorre fora da escola: "a educação informal como aquela na qual os indivíduos aprendem durante seu processo de sociabilização gerada nas relações e relacionamentos intra e extrafamiliares (amigos, escola, religião, clube, etc.)" (GOHN, 2010, p. 16).

Partindo dessa possibilidade de entender-se educação, temos também a educação não formal. $O$ aprendizado produzido no cotidiano das pessoas oferece experiências que podem ser 
trabalhadas em locais diversos, que podem estar vinculadas às instituições, porém desvinculadas de conteúdos curriculares, propostas de ensino e planos de educação escolar.

É o que propõe Gohn (2010): segundo a autora, as práticas da educação não formal se desenvolvem extramuros escolares, nas organizações sociais, nos movimentos, nos programas de formação sobre direitos humanos, cidadania e complementa:

Na educação não formal, os espaços educativos localizam-se em territórios que acompanham as trajetórias de vida dos grupos e indivíduos, fora das escolas, em locais informais, locais onde há processos interativos intencionais (a questão da intencionalidade é um elemento importante de diferenciação) (GOHN, 2010, p. 17).

É no âmbito destas diferenciações entre educação formal, informal e não formal que conduzimos nossas discussões a respeito da diversidade de espaço sócio-ocupacionais para a Pedagogia que tem se despontado no Brasil. Trata-se de práticas que requisitam novos formatos dos cursos de formação de pedagogos/as, a partir da tensão entre objeto de trabalho cultural e historicamente constituído e a novidade das exigências educacionais atuais que colocam novos formatos educativas em contextos diferentes do escolar.

Alguns estudiosos/as, a saber: Franco (2008), Brzezinsk (2007), Miranda e Silva (2017) etc, têm compreendido os estudos dos novos formatos educativos no âmbito da Pedagogia como uma ciência da educação. Entendida como "teoria da educação", evidencia-se que ela é uma teoria da prática; teoria da prática educativa, porque, se toda Pedagogia é teoria da educação, nem toda teoria da educação é Pedagogia. Na verdade, o conceito de Pedagogia se reporta a uma teoria que se estrutura a partir e em função da prática educativa. A Pedagogia, como teoria da educação, busca questionar, de alguma maneira, o problema da relação educador-educando, de modo geral, ou, no caso específico da escola, a relação professor-aluno, orientando o processo de ensino e aprendizagem.

Franco $(2008$, p. 73 ) discute que a Pedagogia, para poder dar conta de seu papel social, deverá definir-se e exercer-se como uma ciência própria, que se liberta dos grilhões de uma ciência clássica e da submissão às diretrizes epistemológicas de ciências auxiliares, a fim de que possa se assumir como uma ciência "que não apenas pensa e teoriza as questões educativas, mas que organiza ações estruturais, que produzem novas condições de exercício pedagógico, 
compatíveis com a expectativa da emancipação da sociedade".

O mesmo ocorre com a formação de docentes por meio do estágio supervisionado. 0 estágio na formação docente será esvaziado de sentido se se orientar por questões vinculadas apenas ao ambiente escolar. No processo de formação inicial não há, na realidade, excesso de teorias, o que existe é uma forma equivocada de trabalhar um currículo de formação: a teoria serve para conduzir o olhar na prática, enquanto a prática precisa fornecer elementos para compreender/tencionar a teoria. Essa formação precisa pautar-se na perspectiva de uma Pedagogia Crítica, que, de alguma forma percebe e visualiza a complexidade das relações educativas (FRANCO, 2008).

Tais questionamentos sobre diferentes tipos de educação e a cientificidade da área pedagógica nos dá condições de problematizar diferentes campos sócio-ocupacionais que têm surgido com a especialização do trabalho pedagógico. Não se trata mais somente da escola. Visando a estabelecer conexões entre teoria e prática no âmbito da formação inicial, as alunas do Curso de Pedagogia foram levadas a pesquisar, em diferentes espaços de suas cidades, os locais onde havia Pedagogia que não voltada à educação escolar. As alunas, originárias de municípios da região leste do Mato Grosso do Sul e da alta região noroeste de São Paulo, fizeram pesquisas em três esferas: poder público (saúde, assistência social), organizações da sociedade civil que prestam serviços ao poder público e Empresas. Abaixo elencamoso retorno dos municípios de Brasilândia/MS, Três Lagoas/MS e Guaraçaí/SP obtido pela pesquisa das alunas.

As estudantes fizeram um levantamento da quantidade de unidades públicas, da sociedade civil e as Empresas. Com esse mapa, fizeram o contato telefônico apresentando o motivo da pesquisa e a possibilidade de fornecimento da informação solicitada: se haveria um profissional de Pedagogia no quadro de colaboradores/as. O referido contato nos oportunizou criar a seguinte representação:

Quadro 1 - Pesquisa de pedagogos/as não escolares

\begin{tabular}{|c|c|c|c|c|c|}
\hline \multicolumn{4}{|c|}{ Quantidades de pedagogos/as em espaços sócio-ocupacionais não escolares } \\
\hline Brasilândia/SP & \multicolumn{2}{c|}{ Guaraçaí/SP } & \multicolumn{2}{c|}{ Três Lagoas/MS } \\
\hline Assistência Social & Saúde & Assistência Social & Saúde & Assistência Social & Saúde \\
\hline Não tem & Não Tem & Não tem & Não tem & 8 & 2 \\
\hline
\end{tabular}

Fonte: Elaborado pelos autores, 2019

As constatações presentes no quadro acima nos revelaram que apenas no poder público 
há pedagogos/as atuação, em políticas sociais, como a saúde e assistência social. Tais áreas conduzem à criação de novos espaços sócio-ocupacionais para a Pedagogia porque a materialização do que é compreendido como uma questão social ou de saúde relaciona-se a um fenômeno complexo da vida social, o qual envolve a disposição da pessoa ou do seu grupo social para ter atitudes que causam vulnerabilidades ou atitudes arriscadas. Entender que, em locais de saúde e de assistência social, os problemas encontrados podem ser tratados como interdisciplinaridade exige um profissional de Pedagogia para articular saberes da área de formação educacional.

No contato realizado com as Secretarias de Saúde e de Assistência Social do município de Três Lagoas, questionamos em quais locais esses/as pedagogos/as estão inseridos. Conhecemos que esses/as profissionais no âmbito da Assistência Social estão em unidades de Centro de Referência de Assistência Social (CRAS), Centro de Referência Especializado de Assistência Social (CREAS). Àquela época, o município de Três Lagoas/MS dispunha de seis unidades de CRAS e uma de CREAS. Já na área da Saúde, a Secretaria retornou que tem dois/duas pedagogos/as, um que atua no Centro de Atenção Psicossocial III (CAPS III) e o outro no Centro de Atenção Psicossocial para tratamento de álcool e outras drogas (CAPS AD).

A partir desse mapeamento, muitas reflexões surgem para que possamos conhecer os porquês do/da Profissional de Pedagogia ser requisitado nesses espaços totalmente diferentes do que a formação inicial oferece. Indagações do tipo: qual demanda há nesses locais que apontam para a necessidade da Pedagogia? Tais locais trazem para o contexto de formação a novidade, uma gama de assuntos a serem analisados para se produzir tanto formação inicial quanto resposta científico-profissional para as demandas que surgem para a Pedagogia nesses lugares.

Sabe-se que a formação dos professores e sua atuação ainda são reduzidas à docência. Porém, Libâneo (2006) nos mostra que a Pedagogia, como ciência da educação, estuda o fenômeno educativo. Portanto, a Pedagogia tem seu campo vasto, pois a prática educativa ocorre em várias instâncias da vida e abrange toda a sociedade:

Pedagogia é, então, o campo do conhecimento que se ocupa do estudo sistemático da educação - do ato educativo, da prática educativa como componente integrante da atividade humana, como fato da vida social, inerente 
ao conjunto dos processos sociais. Não há sociedade sem práticas educativas. Pedagogia diz respeito a uma reflexão sistemática sobre o fenômeno educativo, sobre as práticas educativas, para poder ser uma instância orientadora do trabalho educativo (LIBÂNEO, 2006, p. 6).

Com isso, toda educação corresponde a uma pedagogia. Há uma diversidade de assuntos e campos para se tratar no interior da Pedagogia, ou, poderíamos dizer, Pedagogias. Trazer a Pedagogia como uma concepção plural, com a qual vários campos produzem novas demandas para o saber-fazer pedagógico. Além dos espaços sócio-ocupacionais investigados, saúde e assistência social, acreditamos, se caso tivemos condições de fazer isso, que encontraríamos profissionais da Pedagogia em outros campos e áreas.

\section{Novos espaços sócio-ocupacionais: a Pedagogia na assistência social}

Pretendemos entender, por agora, como a Pedagogia se constrói em relação aos campos diversos de atuação que ela se insere. Assim, procuramos problematizações significativas no campo da assistência social e da saúde, condensando aspectos referentes às necessidades formativas e àquelas que o campo de atuação impõe para pensar em formação inicial, contínua e desenvolvimento profissional dos/das pedagogos/as.

No contexto da Pedagogia na Assistência Social, Otto (2009) afirma que a Pedagogia Social é mais recente do que sua prática, pois já havia tradições e ações voltadas para a perspectiva pedagógico-social que buscava encontrar soluções para problemas que assolam a sociedade, resultados das mudanças sociais que envolvem o avanço da modernidade e da economia; como os problemas relacionados à fome, à miséria, ao abandono.

Isso impõe a necessidade de pensar sobre a formação inicial de pedagogos/as articulada a essa complexidade que os espaços sócio-ocupacionais produzem; trata-se do fato de que a educação enquanto "[...] uma prática social humana é um processo histórico, inconcluso, que emerge da dialeticidade entre homem, mundo, história e circunstância" (FRANCO, 2008, p. 75). Ou seja, é possível encontrar tais demandas em diferentes contextos da vida social.

Assim, a Pedagogia Social tem a intenção de ampliar horizontes de oportunidades de vida e trabalho dessas pessoas, pois fazem parte dos seus direitos sociais. A Pedagogia Social também reconhece e valoriza todos tipos de educação que contribuem para o pleno desenvolvimento do 
cidadão, como a educação formal, não formal e informal.

Nesse sentido, a Pedagogia Social tem como finalidade de pesquisa a promoção de condições de bem-estar social, de convivência, de exercício de cidadania, de promoção social e desenvolvimento, de superação de condições de sofrimento e marginalidade. Tem a ver com a construção, aplicação e avaliação de metodologias de prevenção e recuperação (CALIMAN, 2009, p. 59).

Vê-se que a produção teórica na área da educação sobre a questão da Pedagogia Social tem sido ampla no Brasil. Acreditamos que conhecer diferentes práticas Brasil a fora oportuniza encontrar um conjunto de possibilidades significativas para firmar a Pedagogia Social como uma área de formação específica que adquira espaço no contexto da formação inicial de pedagogos/as como também de outros licenciados/as que exercem as funções de educadores sociais via concursos ou empregos públicos.

Em 2011, por exemplo, Silva (2011) realizou pesquisa de conclusão de curso de Licenciatura em Pedagogia, na qual investigou a atuação de pedagogos/as na Assistência Social do município de Três Lagoas/MS. Àquela época, Silva (2011) mapeou cinco pedagogos/as, dos quais quatro atuavam em CRAS e um no CREAS. Os dados resultantes da pesquisa de Silva (2011) apontam a necessidade reformulação do estatuto epistemológico da Pedagogia que implica a adoção de currículos mais flexíveis para o campo da formação bem como uma análise da dimensão prática dos espaços onde os/as pedagogos/a atuam na política pública de assistência social de âmbito municipal.

Os desdobramentos da pesquisa de Silva (2011) foram retomados e discutidos posteriormente. Assim, a partir da necessidade de deslocar o assunto da Pedagogia Social do campo da adjetivação para o campo da formação teórico-prática do futuro/a pedagogo/a, Silva e Santos (2013, p. 179) afirmam que:

Ao examinar os dados da pesquisa, as preocupações se debruçaram sobre a importância dos pesquisadores e também dos pedagogos que atuam nas instituições de assistência social analisar seus processos formativos e as exigências do campo educacional, sobretudo, as novas configurações do fenômeno educativo no cenário atual.

Segundo os autores, há diferenças entre a educação escolar e a educação social oferecida nas unidades de assistência social. Enquanto a primeira visa a realizar atividades com o objetivo 
de proporcionar acesso a um currículo formalizado, a segunda propõe atividades socioeducativas para a construção e/ou fortalecimento da cidadania e a emancipação de pessoas em situação de vulnerabilidade social (SILVA; SANTOS, 2013).

Os/as pedagogos/as que participaram da pesquisa de Silva (2011) assinalaram de forma bastante enfática as dificuldades que enfrentaram para desenvolver ações educativas com o público atendido pela assistência social. Para dar conta dessas dificuldades, Silva (2011) ressalta que a Pedagogia precisar produzir aspectos teóricos sobre a atuação nessa área, não somente propor discussões breves no espaço de formação inicial. Isso proporciona evitar que a Pedagogia tenha que se submeter a outras áreas para se construir como um campo de produção de saberes teórico-práticos na assistência social

Santos (2014), por sua vez, realizou estudo investigativo na área da educação sobre a atuação de pedagogos/as em espaços educativos não formais ligados à Organizações da Sociedade Civil, conhecidas como ONGs, da cidade de Paranaíba/MS. Buscou, com sua pesquisa, conhecer como ocorre a prática pedagógica nesses espaços que são incluídos na área social e, também, traçar um perfil desse profissional de Pedagogia. Santos (2014) encontrou dez pedagogos/as atuantes na área de assistência social, mas não vinculados ao poder público. Desses profissionais, oito atuam nas equipes executando atividades de trabalho social com enfoque pedagógico e outros dois realizam atividades de gerências das unidades de assistência social.

Em relação ao perfil, Santos (2014, p. 117) afirma:

\begin{abstract}
Sobre o perfil profissional do pedagogo que atua nos espaços de educação não formal, os dados revelaram que ainda muita divergência se existe ou não um perfil para atuar nesses espaços. Em síntese, ficou claro que para as entrevistadas as características essenciais são: ter conhecimento didático; afeto e empatia para se relacionar bem com as crianças.
\end{abstract}

Observa-se que, ao traçar o perfil, Santos (2014) revela que, além de necessidades no campo da profissionalidade, ainda é preciso ter a delicadeza de lidar com as questões sociais e de vulnerabilidade que as crianças e/ou adolescentes apresentam. No que se refere à empatia e ao afeto, os documentos normativos da atuação na assistência social definem que uma das práticas profissionais, além de representar a oferta de proteção social no contexto da assistência 
social, é o agir com a acolhida.

A acolhida é uma segurança social oferecida pela política de assistência social. Com ela, os/as profissionais podem interpretar a realidade da pessoa ou do seu grupo para intervir de forma mais qualificada nas demandas por trabalho social. De acordo com a Política Nacional de Assistência Social (BRASIL, 2004), a acolhida é uma forma segurança aliada a outras ofertas como convívio, renda, autonomia e sobrevivência; assim, a acolhida é:

[...] uma das seguranças primordiais da política de assistência social. Ela opera com a provisão de necessidades humanas que começa com os direitos à alimentação, ao vestuário e ao abrigo, próprios à vida humana em sociedade. A conquista da autonomia na provisão dessas necessidades básicas é a orientação desta segurança da assistência social (BRASIL, 2004, p. 31).

É necessário vincular as necessidades que a Pedagogia Social tem para se constituir como um campo de intervenção na área de assistência social a partir do conteúdo construído por ela. Não significa impor à Pedagogia um saber-fazer de outra área, mas, se a Pedagogia é requisitada nesse local, ela precisa de desenvolver seu campo teórico a partir de demandas próprias da proteção oferecida.

A respeito disso, outro aspecto relevante $=$ abordado na pesquisa de Santos (2014) refere-se às dificuldades de os/das pedagogos/as entenderem aspectos metodológicos. Nesse sentido, Santos (2014, p. 118) observa necessidade de avanços:

\begin{abstract}
Nas ONGs participantes da pesquisa podemos verificar a partir dos dados que, a definição do papel do pedagogo como educador e as atividades que são de sua responsabilidade são claros. Contudo, quanto à construção de metodologias que possibilitem a reflexão científica sobre as práticas desenvolvidas na educação não formal, a fim de consolidar o campo de pesquisa, verificamos que precisa avançar, bem como a delimitação de temáticas voltadas para a formação sociopolítica deste profissional.
\end{abstract}

Independente de qual assunto seja tratado no contexto da educação não escolar que necessita de intervenção pedagógica, Santos (2014) afirma que o profissional enfrenta dificuldades sobre aspectos relacionados à gestão do trabalho na assistência social.

Em 2016, encontramos outro estudo voltado para a atuação de profissionais da Pedagogia na área de Assistência Social. Dessa vez, Miranda (2016) fez levantamento, em 
plataforma do Cadastro de Profissionais do Sistema Único de Assistência Social (SUAS), da relação de pedagogos/as atuando na microrregião de Andradina/SP localizada na Alta Noroste Paulista.

Essa microrregião é composta pelos municípios de “Andradina, Castilho, Guaraçaí, Ilha Solteira, Itapura, Mirandópolis, Murutinga do Sul, Nova Independência, Pereira Barreto, Sud Menucci, Suzanápolis" (MIRANDA, 2016, p. 27). Desses 11 municípios, Miranda (2016) encontrou pedagogos/as atuando em Itapura/SP e Nova Independência/SP. A entrada desses profissionais na área de assistência social foram a seguinte: em Itapura/SP, via concurso público, e, em Nova Independência, via readaptação de servidora.

Diante desses dados encontrados por Miranda (2016), considerando que o município de Itapura/SP apresentou de forma real a necessidade de um profissional de Pedagogia na área social, ela resolveu pesquisar esse município. A partir das interlocuções propostas pela novidade de seu estudo, Miranda (2016) se propôs a compreender aspectos da atuação da profissional de Pedagogia.

Miranda (2016) confirmou que a pedagoga que atuava em Itapura/SP tinha àquela época vínculo com o CRAS e a atuação dos/das profissionais daquele local acontecia via referência. Cada profissional, psicólogo ou assistente social, tinha uma referência de serviço. A pedagoga atuava diretamente como a gestão de serviços relacionados à inclusão, acompanhamento e desligamento de crianças, adolescentes e suas famílias de serviços de fortalecimento de vínculos familiares e comunitários, os antigos projetos sociais para as crianças e adolescentes, hoje com termo próprio dos avanços da área (MIRANDA, 2016).

Em publicação dos resultados de seu estudo (MIRANDA, 2016), Miranda e Silva (2017) constaram que a Pedagogia passa a ser possível na assistência social a partir de 2011 com resolução do Conselho Nacional de Assistência Social (CNAS) que indica tal categoria profissional como parte das equipes de gestão e execução do trabalho social. Miranda e Silva (2017, p. 83) evidenciam aspectos pertinentes à atuação da pedagoga pesquisada:

Com isso, ao ser parte da equipe técnica, a Pedagoga é equiparada como Técnica de Referência (TR), assim como os/as outros/as profissionais que compõem a equipe do CRAS. Entendemos assim que o/a Técnica de Referência como o profissional que desenvolve ações comuns a todos/as, porém agindo conforme a especificidade do conhecimento de sua área. As orientações Técnicas para a ação

Periódico Horizontes - USF - Itatiba, SP - Brasil - e020032 
dos CRAS entendem o/a Técnica de Referência como o/a profissional com formação em Ensino Superior nas áreas do SUAS, sendo que dentre as principais incumbências encontra-se a de atuar com enfoque de algumas metodologias específicas do trabalho social, desde que com experiência mínima de atuação com serviços, programas, planos e projetos de assistência social.

Tal pesquisa confirma que há atividades para os profissionais de referência das famílias no SUAS que são pertinentes a todos/as, porém cada qual desenvolve sua ação com enfoque da sua formação. Essa consideração é importante para entender a necessidade que os saberes têm na articulação com demandas desse novo campo de trabalho para a Pedagogia. Faz-nos afirmar que pedagogos/as não exercem funções de outros/as profissionais, mas atuam de modo interdisciplinar. Significa que, ao surgirem demandas próprias de outras áreas durante as atividades de acompanhamento e orientação realizadas, o/a pedagogo/a terá que solicitar auxílio de outro/a profissional.

Miranda e Silva (2017, p. 84) confirmam que, na formação da pedagoga entrevistada, não houve acesso à informação de que a atuação na assistência social era possível: "Torna-se visível esta afirmativa no que Rosa caracteriza como a não preparação para lidar com o risco, a pobreza e a vulnerabilidade social de pessoas e suas famílias". Outra questão interessante de se pontuar na pesquisa de Miranda e Silva (2017) refere-se ao fato de que as intervenções pedagógicas na assistência social não contam com visibilidade de resultado em curto período de tempo como poderia ocorrer nas unidades escolares.

Desse modo, a proposta de investigação de Miranda e Silva $(2017$, p. 86) evidenciou que a atuação pedagógica na assistência social pode ser retratada sob dois aspectos:

Além disso, estas práticas nos conduzem a duas reflexões. A primeira relacionase ao fato da necessidade que este conhecimento produzido no contexto do CRAS traz para alguns currículos de formação em Pedagogia da região, contribuindo para a desconstrução da Pedagogia voltada apenas para o espaço escolar, como muitos acreditam. A segunda, em destaque para as técnicas empregadas por Rosa, vem dar uma nova perspectiva para o trabalho social com famílias que abandona a ideia de penalização das pessoas pela sua situação de pobreza e outras vulnerabilidades, oferecendo condições de ressignificação de atitudes auto-vulneradoras e dos grupos as quais fazem parte.

Tais reflexões propostas por Miranda e Silva (2017) amparam discussões sobre alterações 
nos currículos de formação de pedagogo/as e, também, aspectos vinculados à adoção de estratégias pedagógicas para intervir em demandas oriundas das necessidades apresentadas pelas pessoas atendidas nos serviços de assistência social, especialmente o CRAS que representa lócus de atuação da pedagoga investigada.

\title{
Novos espaços sócio-ocupacionais: a Pedagogia na saúde mental
}

A inserção do/da pedagogo/a na área da saúde mental acontece após o reconhecimento da necessidade de tratamento ambulatorial e em meio aberto para pessoas e famílias que enfrentam sofrimentos psiquiátricos e uso de álcool e outras drogas. De acordo com o Portal do governo brasileiro Governo Brasileiro, a saúde mental atende às seguintes especificidades de tratamento:

\begin{abstract}
Abrange a atenção a pessoas com necessidades relacionadas a transtornos mentais como depressão, ansiedade, esquizofrenia, transtorno afetivo bipolar, transtorno obsessivo-compulsivo, incluindo aquelas com quadro de uso nocivo e dependência de substâncias psicoativas (álcool, cocaína, crack e outras drogas) (PORTAL DO SUS, 2019, s/p.).
\end{abstract}

No levantamento feito no município de origem das estudantes de Pedagogia, os/as foram encontrados/as pedagogos/as atuantes na saúde mental no município de Três Lagoas em duas modalidades. Um na oferta de serviços voltados aos sofrimentos mentais graves, como o CAPS III e o outro em situações de saúde ligadas ao uso de álcool e outras drogas.

Segundo o Ministério da Saúde, a concepção de saúde mensal tem ideia oposta ao dos antigos manicômios: o agir em saúde mental se faz no espaço de vida da pessoa em tratamento, assim o CAPS 3:

[...] é um serviço de saúde aberto e comunitário do Sistema Único de Saúde (SUS). Ele é um lugar de referência e tratamento para pessoas que sofrem com transtornos mentais, psicoses, neuroses graves e demais quadros, cuja severidade e/ou persistência justifiquem sua permanência num dispositivo de cuidado intensivo, comunitário, personalizado e promotor de vida (BRASIL, 2004, p. 13).

A partir dessas considerações, o CAPS AD realiza o mesmo serviço, porém focado nas 
questões de álcool e outras drogas. Vários profissionais, assim como na assistência social, atuam na definição de projetos terapêuticos para as pessoas atendidas e os seus grupos reconhecidos como família. A Pedagogia, nesse caso, vem complementar o que será proposto no projeto terapêutico dos/das atendidos/as pelas unidades de saúde mental.

Aquino, Saraiva e Braúna (2012) investigaram práticas da Pedagogia no contexto de serviço de saúde mental vinculado à Universidade Federal de Viçosa. As autoras enfatizaram que a Pedagogia trabalha de forma interdisciplinar como outras profissões a fim de chegar à definição de formas de intervenções eficazes nos tratamentos e práticas de cuidado.

Aquino, Saraiva e Braúna (2012, p. 135) destacam as ações de caráter pedagógico, os objetivos e as dificuldades encontradas com as pessoas atendidas:

Destaca-se aqui o trabalho realizado pelo pedagogo, por ser foco de discussão deste estudo. Esse profissional ministra a oficina lúdico-cognitiva, em que são desenvolvidos jogos recreativos e jogos estruturados. O objetivo é o desenvolvimento do sistema funcional da linguagem, funções cognitivas e habilidades numéricas, favorecendo a reintegração às atividades cotidianas. 0 nível de dificuldade é dosado de acordo com o aspecto motivacional e estrutural dos participantes. Atualmente, a pedagoga ministra a oficina de música, onde são trabalhados vários aspectos relacionados à cognição, afetividade e socialização.

Diante disso, nota-se que os recursos da área de formação se organizam pedagogicamente a partir da imersão no contexto das demandas que o campo da saúde mental apresenta. As participantes da pesquisa de Aquino, Saraiva e Braúna (2012) afirmam que a ação, no contexto da saúde mental, apesar de engajada com a questão educativa, funciona de forma diferente do contexto escolar. Inferem, assim, que o/a pedagogo/a precisa estar atento às formas com que os grupos se constituem, se organizam e se relacionam para, a partir desse cenário, propor intervenções pedagógicas.

Com o estudo, Aquino, Saraiva e Braúna (2012, p. 143) também destacam que a imersão no campo da saúde mental propõe: “[...] a necessidade de se repensar a emergência de identidades profissionais, que vão se constituindo em contextos contraditórios e diversos, confirmando que não há uma única direção na formação do pedagogo".

Em investigação sobre o papel da Pedagogia no CAPS na cidade de Caicó, no Estado de Rio Grande do Norte, Vale (2017) se propôs a entender as atividades realizadas pelo profissional, 
onde constatou:

O que pudemos entender é que o pedagogo procura fazer com que os usuários se sintam acolhidos, não somente no momento que chegam ali à procura de atendimento, mas também no momento de realizar uma atividade em que o usuário se supere com sua própria criatividade e possa se sentir acolhido ao ouvir um "parabéns, está ótimo" ou "você é capaz". É desse acolhimento que o pedagogo fala, uma situação que o usuário vivencie e faça toda a diferença para que as demais atividades sejam realizadas com sucesso (VALE, 2017, p. 33).

É um trabalho que envolve uma ação de motivação para que o sujeito atendido se sinta pertencente ao tratamento e aos cuidados prestados. Os cuidados oferecidos em saúde mental representam um lócus de associação entre a pedagogia e as necessidades advindas dessa intervenção. O que nos leva a entender que se torna necessário articular intervenção pedagógica com os cuidados exigidos para o agir em saúde mental.

Outra atividade profissional da Pedagogia no contexto da saúde mental foi encontrada na pesquisa de Santos e Santos (2017). Trata-se de um CAPS em Floriano no Piauí. As autoras se propuseram a observar a atuação da Pedagogia na saúde mental desse CAPS, onde narraram que o Profissional de Pedagogia também orienta pessoas e suas famílias a respeito de organização de atividades de vida diária, rotina e junto a outras profissões se reúnem para dar apoio familiar no tratamento e cuidado ofertados.

Pode-se constatar que o pedagogo no CAPS observado desenvolve em sua prática uma diversidade de atividades como, por exemplo, atendimento aos familiares dos usuários. Este entendimento foi feito de forma individual e/ou em grupo e teve por objetivo esclarecer a família sobre a condição na qual o usuário se encontrava, assim como também criar vínculos entre as famílias e laços de fraternidade. Pode-se dizer que este momento concorre para que os participantes troquem experiências sobre as situações vividas em relação às questões enfrentadas relativas aos transtornos mentais dos usuários (SANTOS; SANTOS, 2017, p. 6).

A partir dessas atividades, nota-se que a Pedagogia na saúde mental realiza outras possibilidades para entender que o seu campo sócio-ocupacional não é restrito apenas à especialização do trabalho pedagógico no ambiente escolar. Tanto a Pedagogia na Assistência Social quanto a Pedagogia na Saúde Mental, no âmbito das pesquisas, vêm adquirindo visibilidade em diferentes regiões brasileiras. Porém, no que se refere às questões de cunho 
teórico-metodológicas, ainda é notável o ritmo dos estudos se mostra reduzido.

O reconhecimento de que as situações de vulnerabilidade na área de assistência social e, também, na área da saúde requer visões profissionais e técnicas de diferentes áreas oportuniza refletir sobre a necessidade de o conhecimento pedagógico problematizar questões advindas desses contextos de atuação.

\section{Considerações Finais}

A partir da problematização empírica dos dados fornecidos pelas unidades de Secretarias vinculadas às Prefeituras das cidades contatadas, pudemos constatar dois novos campos de atuação que se despontaram a partir de uma leitura das últimas DCN (2006) da Pedagogia, a assistência social e a saúde mental. Trata-se de duas áreas que têm um trabalho direcionado a um público específico: pessoas e grupos vulneráveis com questões próprias da assistência social ou da saúde mental.

A Pedagogia, nesses locais, dada a pluralidade interdisciplinar que as demandas apresentam, presta-se à adoção de intervenções com base no conhecimento pedagógico entrelaçada com a profissionalidade de outras áreas. Leva-nos a confirmar que a Pedagogia produz conhecimento advindo da profissionalidade que esses espaços requerem. Necessita-se, com isso, de que a produção do conhecimento científico na área educacional acompanhe a execução do trabalho pedagógico realizado nesses novos locais de atuação.

Enquanto alguns municípios não contam o/a profissional de Pedagogia nas equipes das unidades de assistência social e saúde mental, outros o fazem, o que leva a caracterizar que as equipes são formadas de acordo com o nível de compreensão sobre a necessidade da Pedagogia para composição das equipes nessas unidades, além das demandas apresentarem serviços que profissionalmente representam atividades da Pedagogia.

Silva (2011), Silva e Santos (2013), Miranda e Silva (2013) e outras realizaram pesquisa sobre a Pedagogia não escolar. Tais autores/as confirmam que a Pedagogia não escolar tem proposto práticas de ensino diferenciadas do ambiente da escola, porque ela precisa de se adequar às necessidades técnicas das demandas da área nova em que se insere. Contudo, essa adequação tem sido feita de maneira muito vagarosa, o que demanda estudos, eventos e 
atividades que forneçam formação contínua ou cursos e possibilitem conhecimento para esses/as pedagogos/as não escolares.

As pesquisas de Silva (2011), Miranda (2016) e Vale (2017) demonstram que há várias funções definidas para os/as profissionais/as de ensino superior que em muitos casos precisa se adequar ao foco da formação. Isso define a dificuldade que o/a profissional de Pedagogia enfrenta para compreender aspectos interventivos de seu papel.

Funções são definidas para os/as profissionais, em muitos casos, independentemente de áreas de formação; porém, pode ser que não estejam considerando o foco formativo. Isso requer preocupação, porque pode ser que pedagogos/as estejam desenvolvendo ações que são atribuições de profissionais do Serviço Social, Psicologia, Terapia Ocupacional... São necessários, então, diálogos interdisciplinares acerca do público atendido, da leitura de demanda, de ações próprias dos aspectos formativos e interventivos de cada profissão.

Problematizar atuação nos espaços não escolares visa entender o que é ação sóciopedagógica ou de caráter interventivo pedagógico na saúde mental, evitando que a atuação interdisciplinar seja interpretada de forma errônea e o/a pedagogo/a desenvolva ações que não seja de sua área de atuação.

\section{Referências}

AQUINO, S. L.; SARAIVA, A. C. L. C.; BRAÚNA, R. de C. A. Representações sociais da atuação do pedagogo na saúde: saberes envolvidos e experiências compartilhadas. Interfaces da educação, Paranaíba, v. 3, n. 7, p. 128-145, 2012. Disponível em: https://periodicosonline.uems.br/index.php/interfaces/article/view/578. Acesso em: 18 Set 2019.

BRASIL. Resolução n. 1, de 15 de maio de 2006. Institui diretrizes curriculares nacionais para o curso de graduação em pedagogia, licenciatura. Brasília, 2006. Disponível em: http://portal.mec.gov.br/cne/arquivos/pdf/rcp01_06.pdf. Acesso em: 24 Jan 2020.

BRASIL. Lei n. 8069, de 13 de Julho de 1990. Dispõe sobre o Estatuto da Criança e do Adolescente. Brasília, 1990. Disponível em: http://www.planalto.gov.br/ccivil_03/leis/l8069.htm. Acesso em: 18 Jun 2019.

BRASIL. Política Nacional de Assistência Social. Brasília: Ministério do Desenvolvimento Social e Combate à Fome, 2004. Disponível em: 
http://www.mds.gov.br/webarquivos/publicacao/assistencia_social/Normativas/PNAS2004.pdf. Acesso em: 10 Out 2019.

BRASIL. Saúde mental no SUS: os centros de atenção psicossociais. Brasília: Ministério da Saúde, 2004. Disponível em: http://www.ccs.saude.gov.br/saude_mental/pdf/sm_sus.pdf. Acesso em: 10 Out 2019.

BRZEZINSK, I. Formação de professores para a educação básica e o Curso de Pedagogia: a tensão entre instituído e instituinte. Revista Brasileira de Política e Administração da Educação RBPAE, Porto Alegre, v.23, n.2, p. 229-251, mai./ago. 2007. Disponível em: https://seer.ufrgs.br/rbpae/article/view/19127. Acesso: 18 Mai 2019.

CALIMAN, G. A Pedagogia Social na Itália. In: SILVA; Roberto da; SOUZA NETO, J. C.; MOURA, R. A. (Orgs) Pedagogia Social. 1a ed. São Paulo: Expressão e Arte Editora, 2009. p. 51-60.

CRUZ, G. B. da. Curso de Pedagogia no Brasil: história e formação com pedagogos/as primordiais. 1ạ ed. Rio de Janeiro: WAK Editora, 2011.

DEMO, P. Pesquisa e construção do conhecimento: metodologia científica no caminho de Habermas. 1ạ ed. Rio de Janeiro: Tempo Brasileiro, 1994.

FRANCO, M. A. S. Pedagogia como ciência da educação. 2ª ed. São Paulo: Cortez, 2008.

GADOTTI, M. A questão da educação formal/não formal. Institut internationa des droits de l'enfant (ide). Droit à l'éducation: solution à tous les problèmes ou problème sans solution? Sion (Suisse), 2005. Disponível em:

http://www.aedmoodle.ufpa.br/pluginfile.php/305950/mod_resource/content/1/Educacao_For mal_Nao_Formal_2005.pdf. Acesso em: 18 Set 2019.

GOHN, M. da G. Educação não formal e o educador social: atuação no desenvolvimento de projetos sociais. 1a ed. São Paulo: Cortez, 2010.

LIBÂNEO, J. C. Didática. 1ạ ed. São Paulo: Cortez, 1994.

LIBÂNEO, J. C. Diretrizes curriculares da Pedagogia imprecisões teóricas e concepção estreita da formação profissional de educadores. Educação e Sociedade, Campinas, v. 27, n. 96 Especial, p. 843-876, out/dez. 2006. Disponível em: http://www.scielo.br/pdf/es/v27n96/a11v2796. Acesso em: 15 Jun 2019.

LIMA, T. C. S. de; MIOTO, R. C. T. Procedimentos metodológicos na construção do conhecimento científico: a pesquisa bibliográfica. Revista katálysis, Florianópolis, v. 10, n. esp. p. 37-45. 2007. Disponível em: http://www.scielo.br/pdf/rk/v10nspe/a0410spe.pdf. Acesso em: 18 Ago 2019.

MIRANDA, B. dos A. Problematizando a formação e a atuação de pedagogos/as a partir de um 
estudo de caso no CRAS de Itapura/SP. Monografia (Licenciatura em Pedagogia) - Associação de Ensino e Cultura de Mato Grosso do Sul, Três Lagoas, 2016

MIRANDA, B. dos A., SILVA, F. G. O. da. Pedagogia Social nos CRAS: novos entrecruzamentos identitários para os/as Pedagogos/as. Revista Emancipação, Ponta Grossa, v. 17, n. 1, p. 74-89. 2017. Disponível em: https://www.revistas2.uepg.br/index.php/emancipacao/article/view/9681/6168. Acesso em: 19 Set 2019.

OTTO, H.-U. Origens da Pedagogia Social. In: SILVA; Roberto da; SOUZA NETO, José Clemente; MOURA, Rogério A. (Orgs) Pedagogia Social. 1ạ ed. São Paulo: Expressão e Arte Editora, 2009. p. 29-42.

PORTAL DO SUS. Saúde mental: o que é, doenças, tratamentos e direito? Ministério da Saúde, 2019. Disponínvel em: http://www.saude.gov.br/saude-de-a-z/saude-mental. Acesso em: 10 Out 2019.

SANTOS, S. S. O pedagogo e os espaços educativos não-formais: conhecendo as organizações não-governamentais (ONGs) de Paranaíba/MS. 2014. 124f. Dissertação (Mestrado em Educação) - Universidade Estadual de Mato Grosso do Sul, Paranaíba, 2014.

SANTOS, P. N. dos; SANTOS, M. C. dos. O centro de atenção psicossocial (CAPS) como alternativa de atuação do pedagogo: relato de uma experiência. In: XII CONGRESSO NACIONAL DE EDUCAÇÃO, Curitiba. Anais [...]. Curitiba: inserir instituição, 2017. p. 498-507. Disponível em: https://educere.bruc.com.br/arquivo/pdf2017/24710_11958.pdf. Acesso em: 10 Out 2019.

SILVA, F. G. O. da. Pedagogos e a Pedagogia social: quais possibilidades de ação? Monografia (Licenciatura em Pedagogia) - Universidade Federal e Mato Grosso do Sul, Três Lagoas, 2011.

SILVA, F. G. O. da; SANTOS, V. L. F. dos. A Pedagogia Social: da adjetivação à construção de um campo de atuação de Pedagogos. In: CIRIACO, K, T; BEZERRA, G, F. Educação básica, formação de Professores e inclusão: práticas e processos educacionais em diferentes cenários. Curitiba: Editora CRV, 2013, p. 177-190.

VALE, S. A. O papel do pedagogo em um centro de atenção psicossocial: uma análise a partir do CAPS AD de Caicó/RN. Monografia (Licenciatura em Pedagogia) - Universidade Federal do Rio Grande do Norte, Caicó, 2017.

Recebido em novembro 2019.

Aprovado em maio 2020. 